\title{
Dual bronchodilation vs triple therapy in the "real-life" COPD DACCORD study
}

This article was published in the following Dove Press journal:

International Journal of COPD

\section{Roland Buhl' \\ Carl-Peter Criée ${ }^{2}$ \\ Peter Kardos ${ }^{3}$ \\ Claus F Vogelmeier ${ }^{4}$ \\ Konstantinos Kostikas ${ }^{5}$ \\ Nadine S Lossi ${ }^{6}$ \\ Heinrich Worth ${ }^{7}$ \\ 'Pulmonary Department, Mainz \\ University Hospital, Mainz, \\ ${ }^{2}$ Department of Sleep and Respiratory \\ Medicine, Evangelical Hospital \\ Goettingen-Weende, Bovenden, \\ ${ }^{3}$ Group Practice and Centre for \\ Allergy, Respiratory and Sleep \\ Medicine, Red Cross Maingau \\ Hospital, Frankfurt am Main, \\ ${ }^{4}$ Department of Medicine, Pulmonary and Critical Care Medicine, University \\ Medical Center Giessen and \\ Marburg, Philipps-University Marburg, \\ Member of the German Center \\ for Lung Research (DZL), Marburg, \\ Germany; ${ }^{5}$ WorldWide Medical Affairs \\ Respiratory, Novartis Pharma AG, \\ Basel, Switzerland; ${ }^{6}$ Clinical Research, \\ Respiratory, Novartis Pharma GmbH, \\ Nürnberg, ${ }^{7}$ Facharztforum Fürth, \\ Fürth, Germany}

Correspondence: Roland Buhl

Pulmonary Department, Mainz University

Hospital, 55 I3I Mainz, Germany

Tel $+496 / 3$ |I7 7270

Email roland.buhl@unimedizin-mainz.de
Background: No observational studies have evaluated the "real-world" effectiveness of dual bronchodilation comprising a long-acting $\beta_{2}$-agonist plus a long-acting muscarinic antagonist vs that of triple therapy (long-acting $\beta_{2}$-agonist plus long-acting muscarinic antagonist plus inhaled corticosteroid) in COPD.

Materials and methods: DACCORD is a non-interventional, observational clinical study that recruited patients following COPD maintenance therapy initiation or change in maintenance therapy between or within therapeutic class. Given the non-interventional nature of the study, the decision to initiate or change medication had to be made by the patients' physicians prior to inclusion in DACCORD. We used a matched-pairs analysis to compare disease progression in two patient groups: those receiving dual bronchodilation vs those receiving triple therapy (each group $\mathrm{n}=1,046$ ).

Results: In two subgroups of patients matched according to a broad range of demographic and disease characteristics, over 1 year, fewer patients receiving dual bronchodilation exacerbated than those receiving triple therapy $(15.5 \%$ vs $26.6 \% ; P<0.001)$, with a greater improvement from baseline in COPD Assessment Test total score at 1 year (mean \pm SD $-2.9 \pm 5.8$ vs $-1.4 \pm 5.5$; $P<0.001)$. When analyzed according to prior therapy, the highest rate of exacerbations was in patients on triple therapy prior to the study who remained on triple therapy. Those changing from mono-bronchodilator to dual bronchodilation had the greatest COPD Assessment Test total score improvement.

Conclusion: In this "real-life" cohort of patients with COPD, most of whom had not exacerbated in the 6 months prior to entry, triple therapy did not seem to improve outcomes compared with dual bronchodilation in terms of either exacerbations or health status. Our analyses clearly demonstrate the potential impact of prior medication on study results, something that should be taken into account when interpreting the results even of controlled clinical trials.

Keywords: acute exacerbations of COPD, bronchodilator, COPD, COPD course and therapy, health-related quality of life

\section{Introduction}

A comparison of particular interest in the management of COPD is dual bronchodilation vs triple therapy, as evaluated in a small number of interventional studies. ${ }^{1-4}$ Although such studies are useful, detailed inclusion and exclusion criteria mean that they typically recruit narrow, selected populations. Non-interventional, observational studies with limited or no inclusion/exclusion criteria, therefore, provide complementary information. However, to date, no observational studies have compared the "real-world" effectiveness of dual bronchodilation and triple therapy.

DACCORD is an ongoing, non-interventional, observational clinical study being conducted in primary and secondary care throughout Germany. ${ }^{5}$ Other than that all 
patients were to have either newly initiated or changed COPD maintenance therapy between or within therapeutic class, the study protocol does not mandate any treatment intervention. Patients have been recruited into two cohorts: in the first cohort, approximately two-thirds of patients started or switched to a treatment regimen including the long-acting muscarinic antagonist (LAMA) glycopyrronium prior to entry; ${ }^{6-9}$ in the second cohort, approximately two-thirds of patients either started or switched to a regimen containing a long-acting $\beta_{2}$-agonist (LABA) plus LAMA fixed-dose combination (FDC) prior to entry. ${ }^{10}$ Patients in both cohorts were also permitted inhaled corticosteroid (ICS).

To avoid imbalances in disease characteristics and/or demographics impacting the efficacy or safety analyses, randomized controlled trials usually stratify randomization into treatment arms. In contrast, to avoid the study process influencing the treatment that patients receive, observational studies typically do not stratify randomization. This means that typical multi-arm, non-interventional, observational studies have populations that differ between arms in terms of patient or disease characteristics, which can complicate the evaluation of comparative treatment effectiveness. A matched-pairs analysis is one way of overcoming such complications in two-arm observational studies. In such analyses, pairs of patients are selected from the two arms, matched by selected demographic and disease characteristics.

In the current manuscript, we pooled data from the two DACCORD cohorts and used a matched-pairs analysis to compare disease progression in two groups of patients: those receiving dual bronchodilation with a LABA plus a LAMA as a fixed or free combination (dual bronchodilation) and those receiving triple therapy of a LABA plus a LAMA and an ICS. Given the results from the WISDOM and FLAME studies, ${ }^{2,11}$ our hypothesis was that in this "real-world" population, the outcomes would be similar in patients receiving dual bronchodilation to those receiving triple therapy.

\section{Materials and methods Study design}

As this is a non-interventional study, specific visits are not mandated by the protocol. However, consistent with usual care in Germany, it was anticipated that data would be recorded approximately every 3 months. At the baseline visit, data collected in Internet-based electronic case report forms included demographic and disease characteristics, prescribed COPD medication, COPD Assessment Test (CAT), modified Medical Research Council dyspnea scale (mMRC), forced expiratory volume in 1 second, and exacerbations in the 6 months prior to entry (requiring oral corticosteroids and/or antibiotics or hospitalization). We collected 6-month historical exacerbation results to minimize the potential impact of patient recall on data accuracy. At 3-monthly visits, exacerbation data were collected, and at the 1-year visit, CAT and exacerbation data were collected. Full details of the methods have been previously published, ${ }^{5}$ as well as the detailed baseline characteristics of the patients recruited into the first cohort ${ }^{8}$ and the first year follow-up data from the first ${ }^{6}$ and second cohorts. ${ }^{10}$

\section{Study population}

The main inclusion criteria were a diagnosis of COPD fulfilling the German COPD Disease Management Program criteria (one of which is that the diagnosis of COPD is confirmed by spirometry testing), age $\geq 40$ years, and initiating or changing COPD maintenance medication. A patient was eligible for inclusion if the change in medication was either between or within therapeutic class (eg, from one LAMA to another). Given the non-interventional nature of the study, the decision to initiate or change medication had to be made by the patients' physicians prior to inclusion in DACCORD. In order to recruit as broad a population as possible, patients were excluded only if they were in the asthma Disease Management Program, or if they were participating in a randomized clinical trial. The study is registered in the European Network of Centers for Pharmacoepidemiology and Pharmacovigilance (Registry Number EUPAS4207), and was approved by the ethics committee of the University of Erlangen-Nuremberg. All patients provided written informed consent prior to inclusion.

\section{Sample size and statistical methods}

There was no specific sample size calculation for the analyses reported here or for the overall DACCORD study. The overall size of the study was determined by a need to collect data that are representative of COPD management throughout Germany. Cohort 1 aimed to recruit $\sim 6,000$ patients, with Cohort 2 recruiting a further 6,000 patients.

The analyses reported in this manuscript are for only those patients who on entry to DACCORD were receiving a LABA plus a LAMA or a LABA plus a LAMA and an ICS, and who continued to receive these regimens throughout the 1-year follow-up. Since the aim was to compare these groups, to permit a "like with like" comparison as far as possible, we used a matched-pairs approach. To select the parameters on which to match the patients, we initially compared the demographic and disease characteristics of the overall group of patients 
who on entering DACCORD were receiving dual bronchodilation with those receiving triple therapy. We identified the parameters that were significantly different between the groups, and from this list we selected those parameters that (1) the "real-world" nature of the study meant that the type and quality of data permitted matching (eg, COPD duration is only captured in the database as $\leq 1$ year and $>1$ year, and so does not sufficiently differentiate between patients);

(2) did not overlap in terms of the characteristic captured;

(3) are known to be linked to exacerbation risk (such as exacerbation history); and (4) resulted in populations of sufficient size to draw conclusions (eg, including prior medication in the matching would have excluded a high proportion of patients). The parameters that we selected were gender, age, body mass index, CAT total score $(<10$, $10-\leq 20,21-\leq 30$, and $>30$ ), lung function (Global Initiative for Chronic Obstructive Lung Disease [GOLD] spirometric grades), exacerbation history (yes/no), and smoking history (smokers, non-smokers, ex-smokers).

For the between-group comparisons of the baseline characteristics, categorical variables were univariately checked for independence from treatment groups using the chi-squared test, with continuous variables tested for equal distribution using Wilcoxon rank sum test. Exacerbation rates were estimated using a negative binomial regression model with annualized numbers of exacerbation as the dependent variable and treatment group as the independent variable. For CAT total score, mean values are presented, together with the proportion of patients with clinically relevant (ie, $\geq 2$ unit) changes from baseline - either improvement or worsening.

\section{Results}

\section{Participants}

A total of 12,382 patients were recruited into the two cohorts, with 8,201 completing the 1-year visit, 2,885 of whom were receiving $\mathrm{LABA}+\mathrm{LAMA}$ and 1,311 were receiving triple therapy (Figure 1 and Table S1). The subsequent pairmatching process selected 1,046 patients in each group, who were included in the subsequent analyses.

\section{Matched-pairs analysis}

\section{Baseline characteristics}

As shown in Table S1, the pair-matching process resulted in two cohorts that were very similar in terms of baseline demographics and disease characteristics. A higher proportion of patients in the triple therapy group had disease duration of $>1$ year, and a higher proportion had mMRC score $\geq 2$. In addition, although overall, a similar proportion of patients had at least one comorbidity, the proportion of patients with diabetes mellitus type 2 was lower in the triple therapy group. In the LABA+LAMA group, a total of 797 patients $(76 \%)$ were receiving their medication as a LABA/LAMA combination inhaler, with 249 patients (24\%) receiving separate inhalers. In the triple group, 770 patients (74\%) were receiving a LABA/ICS single combination inhaler plus a separate LAMA, 141 patients (13\%) were receiving a LABA/LAMA combination inhaler plus a separate ICS, and 135 patients (13\%) were receiving ICS, LABA, and LAMA in three separate inhalers.

\section{Treatment effectiveness}

Over the 1-year follow-up, significantly fewer patients in the LABA+LAMA group experienced an exacerbation (15.5\% vs $26.6 \% ; P<0.001)$, with a rate of exacerbations significantly lower than in the triple therapy group $(0.184$ [95\% confidence limit $0.156,0.216]$ vs 0.364 [0.320, 0.414]; $P<0.001)$. Furthermore, after 12 months, patients in the LABA+LAMA group had a significantly greater improvement from baseline in the CAT total score (mean $\pm \mathrm{SD}-2.9 \pm 5.8$ vs $-1.4 \pm 5.5$; $P<0.001$ ), with a significantly greater proportion of patients having a clinically relevant improvement compared to the triple therapy group $(61.8 \%$ vs $47.2 \% ; P<0.001)$.

\section{Prior COPD maintenance medication}

Given that the disease and demographic characteristics of the two groups were matched at baseline, these results (with dual bronchodilation consistently statistically superior to triple therapy) were counterintuitive. To better understand this phenomenon, we also compared the prior medication in the two groups. As can be seen in Figure 2, there was a substantial imbalance in prior COPD maintenance medication between the two groups.

\section{Analysis by prior therapy}

\section{Baseline characteristics}

To evaluate the effect of prior medication, we grouped the patients as follows: patients in the LABA+LAMA group who were 1) previously receiving a single bronchodilator (ie, added a bronchodilator on entry) or 2) previously receiving $\mathrm{LABA}+\mathrm{LAMA}$ (ie, remained on $\mathrm{LABA}+\mathrm{LAMA}$ substance classes, although with a change in at least one of the molecules); and patients in the triple therapy group who were 3) previously receiving LABA+ICS or LAMA+ICS (ie, added a bronchodilator on entry) or 4) previously 


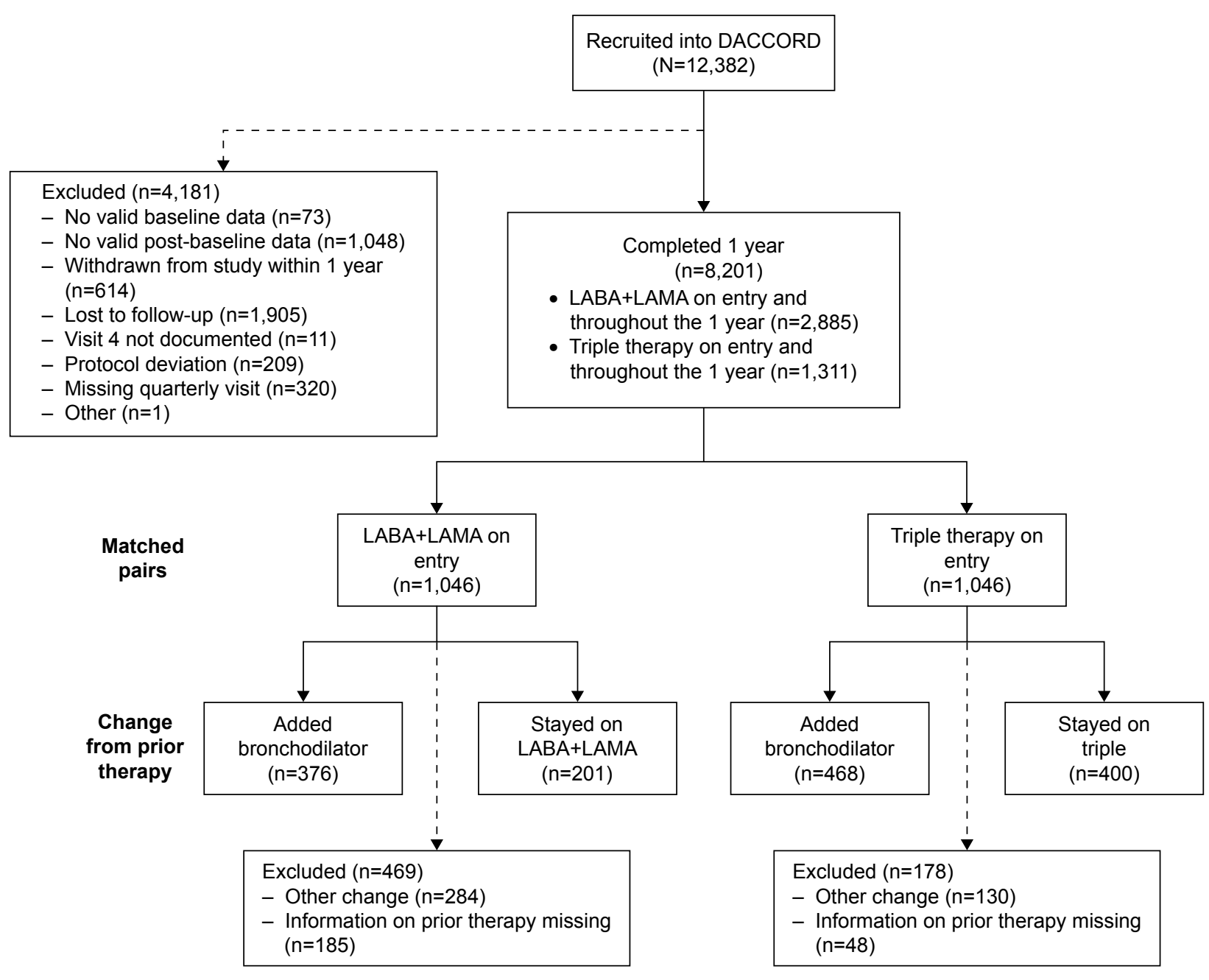

Figure I Patient disposition, including numbers of patients included in the initial matched-pairs analysis and those included in the subsequent analyses by prior COPD maintenance therapy.

Abbreviations: ICS, inhaled corticosteroid; LABA, long-acting $\beta_{2}$-agonist; LAMA, long-acting muscarinic antagonist.

receiving triple therapy (ie, remained on triple therapy, although with a change in at least one of the molecules). The parameters included in the original pair matching were still reasonably well balanced across subgroups (Table 1). Those patients who stayed on LABA+LAMA or triple therapy were slightly less likely to have a history of exacerbations than those who added a bronchodilator, and those who stayed on LABA+LAMA had a slightly better (ie, lower) CAT total score than the other groups. In terms of the parameters that were not included in the pair matching, patients who stayed on LABA+LAMA or triple therapy were more likely to have been diagnosed $>1$ year prior to study entry than those who added a bronchodilator.

\section{Treatment effectiveness}

Most of the patients included in this analysis did not exacerbate over the 1-year follow-up. The highest percentage of patients exacerbating during the 1-year follow-up was in the group of patients on triple therapy prior to the study who remained on triple therapy (Figure 3). This group also had the highest rate of exacerbations during the 1-year follow-up (Figure 4). Furthermore, $7.5 \%$ of the patients who stayed on triple therapy had two or more exacerbations over this period, compared with $6.6 \%$ of the patients who added a bronchodilator to receive triple therapy and $3.5 \%$ of patients in the two LABA+LAMA groups.

The group to have the greatest benefit in terms of CAT total score at 12 months was of those changing from a mono-LABA or mono-LAMA to LABA+LAMA on entry, with a clinically relevant improvement in mean total score and nearly two-thirds of patients having a clinically relevant improvement (Table 2). The group of patients who remained on triple therapy had an overall improvement in CAT total score that was below the threshold of clinical relevance, with nearly a third of patients having a clinically relevant worsening, whereas less than one-fifth of patients 


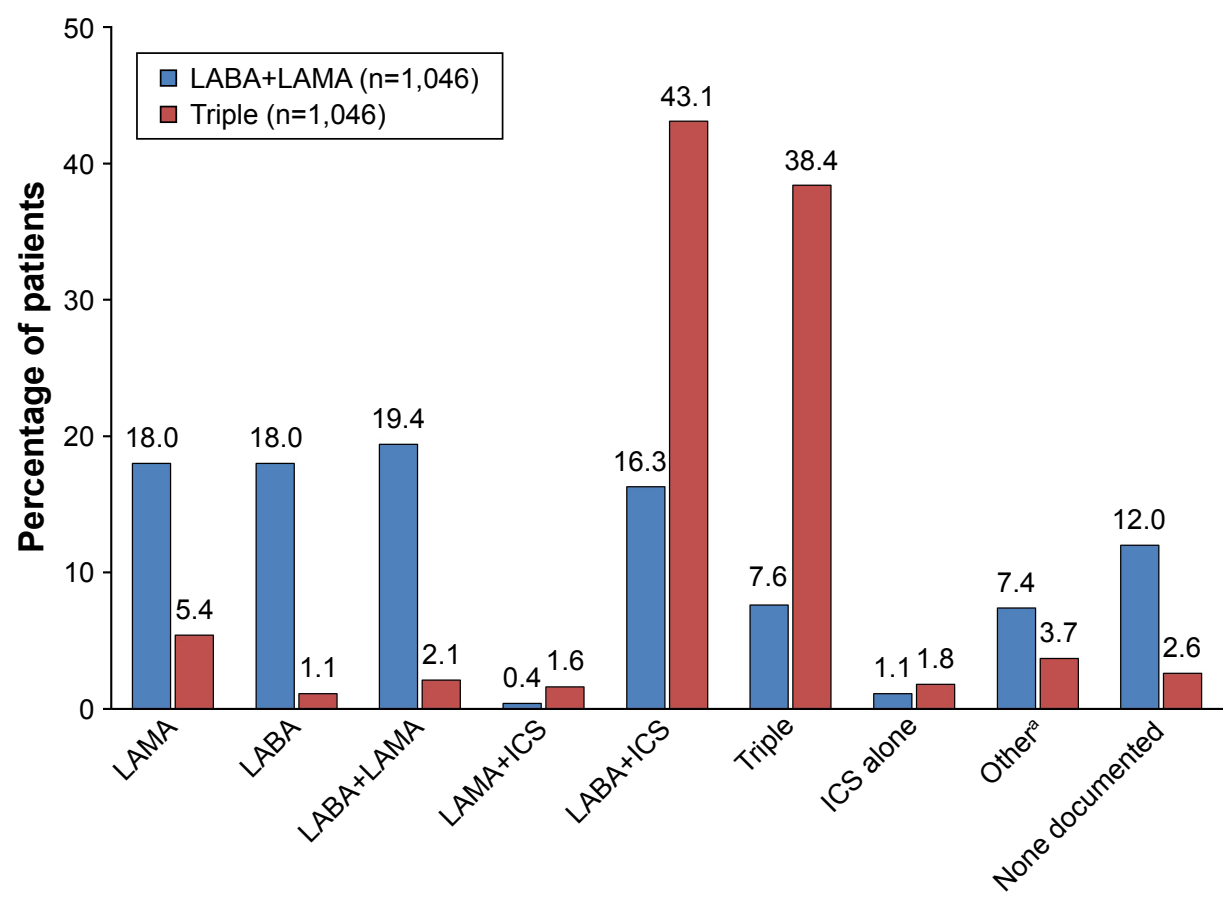

Prior therapy

Figure 2 Prior therapy, according to post-baseline treatment group in the matched-pair analysis $(n=2,092)$.

Note: ancludes patients receiving only short-acting bronchodilators and those receiving regimens containing theophylline and/or phosphodiesterase-4 inhibitors.

Abbreviations: ICS, inhaled corticosteroid; LABA, long-acting $\beta_{2}$-agonist; LAMA, long-acting muscarinic antagonist.

who added a bronchodilator to receive triple therapy had a clinically relevant worsening. Although approximately half of the patients who stayed on LABA+LAMA had a clinically relevant improvement in CAT, the mean improvement from baseline in CAT total score was not clinically relevant.

\section{Discussion}

This is the first study to compare the "real-world" effectiveness of dual LABA+LAMA bronchodilation with that of triple therapy. We used a matched-pairs approach, based on a broad range of demographic and disease characteristics. This successfully resulted in two cohorts that were matched across a broad range of parameters beyond those used in the pair matching. Over the subsequent 1-year follow-up period, LABA+LAMA therapy was superior to triple therapy in terms of both exacerbations and health status (CAT total score), with statistically significant differences between the two groups. However, differences in prior medication potentially influenced these results, as shown in a series of additional analyses with patients grouped not only according to therapy received on entry to and during the study, but also the prior therapy. This gave us four groups large enough to draw conclusions - those who stayed on dual bronchodilation or triple therapy, and those who added a bronchodilator to receive either dual bronchodilation or triple therapy. Importantly, despite this subgrouping, the baseline characteristics still remained well balanced.

The analyses of these four subgroups clearly demonstrate how prior therapy can influence subsequent results. This is something that controlled trials rarely take into account with the design of such studies often resulting in patients being "homogenized" onto either minimum (eg, short-acting bronchodilator) or maximum medication (eg, in WISDOM ${ }^{2}$ ) during a run-in period. As a consequence, controlled studies overlook (or at least reduce) the opportunity to determine which patients will respond to therapies under "real-life" conditions. It is important that when interpreting any trial, readers consider the potential influence of patient selection and prior therapy, not only on the results of the trial but also on the generalizability and applicability of the findings. The group to gain most benefit from therapy over the 1-year follow-up was those previously receiving monotherapy with a LABA or a LAMA who added a second bronchodilator. This group had the lowest exacerbation rate of the four analyzed, with a clinically relevant improvement in mean CAT total score and the highest proportion of patients with a clinically relevant improvement in health status, gaining more benefit from the therapy change than the group adding another bronchodilator to ICS plus bronchodilator therapy. In contrast, the group that remained on triple therapy had the highest exacerbation rate, the highest percentage exacerbating, and 
Table I Baseline demographics and disease characteristics of patients subgrouped according to prior therapy

\begin{tabular}{|c|c|c|c|c|}
\hline \multirow{2}{*}{$\frac{\text { Baseline therapy }}{\text { Change from prior therapy }}$} & \multicolumn{2}{|l|}{ LABA+LAMA } & \multicolumn{2}{|l|}{ Triple } \\
\hline & $\begin{array}{l}\text { Added } \\
\text { bronchodilator } \\
(n=376)\end{array}$ & $\begin{array}{l}\text { Stayed on } \\
\text { LABA+LAMA } \\
(\mathrm{n}=\mathbf{2 0} \mathrm{I})\end{array}$ & $\begin{array}{l}\text { Added } \\
\text { bronchodilator } \\
(n=468)\end{array}$ & $\begin{array}{l}\text { Stayed } \\
\text { on triple } \\
(n=400)\end{array}$ \\
\hline \multicolumn{5}{|l|}{ Gender, n (\%) ${ }^{\mathrm{a}}$} \\
\hline Male & $243(64.6)$ & 132 (65.7) & $308(65.8)$ & $254(63.5)$ \\
\hline Age (years) ${ }^{\mathrm{a}}$ & $66.4 \pm 9.9$ & $67.4 \pm 9.5$ & $66.4 \pm 10.2$ & $67.4 \pm 9.6$ \\
\hline \multicolumn{5}{|l|}{ Age groups, n (\%) } \\
\hline$<65$ & $156(4 \mid .5)$ & $82(40.8)$ & $206(44.0)$ & I5I (37.8) \\
\hline $65-75$ & $144(38.3)$ & $73(36.3)$ & $170(36.3)$ & $166(4 \mid .5)$ \\
\hline$>75$ & $76(20.2)$ & $46(22.9)$ & $92(19.7)$ & $83(20.8)$ \\
\hline BMI $\left(\mathrm{kg} / \mathrm{m}^{2}\right)^{\mathrm{a}}$ & $27.6 \pm 5.6$ & $27.7 \pm 5.2$ & $27.7 \pm 4.8$ & $27.2 \pm 5.8$ \\
\hline \multicolumn{5}{|l|}{ Time since primary diagnosis, $\mathrm{n}(\%)$} \\
\hline$\leq$ I year & $93(24.7)$ & $27(13.4)$ & $79(16.9)$ & $52(13.0)$ \\
\hline$>$ I year & $283(75.3)$ & $174(86.6)$ & $389(83.1)$ & $348(87.0)$ \\
\hline \multicolumn{5}{|l|}{ Smoking history, $\mathrm{n}(\%)^{\mathrm{a}}$} \\
\hline Ex-smoker & $194(51.6)$ & III (55.2) & $238(50.9)$ & $221(55.3)$ \\
\hline Current smoker & $132(35.1)$ & $69(34.3)$ & $165(35.3)$ & $120(30.0)$ \\
\hline Non-smoker & $50(13.3)$ & $21(10.4)$ & $65(13.9)$ & $59(14.8)$ \\
\hline \multicolumn{5}{|l|}{$\mathrm{FEV}_{1} \%$ predicted, $\mathrm{n}(\%)^{\mathrm{a}, \mathrm{b}}$} \\
\hline$\geq 80 \%$ & $45(12.0)$ & $16(8.0)$ & $64(13.7)$ & $4 \mathrm{I}(10.3)$ \\
\hline $50 \leq \mathrm{FEV}_{1}<80 \%$ & $230(6 \mid .2)$ & $108(53.7)$ & $277(59.2)$ & $222(55.5)$ \\
\hline $30 \leq \mathrm{FEV}_{1}<50 \%$ & $94(25.0)$ & $73(36.3)$ & $117(25.0)$ & $122(30.5)$ \\
\hline$<30 \%$ & $7(1.9)$ & $4(2.0)$ & $10(2.1)$ & $15(3.8)$ \\
\hline \multicolumn{5}{|c|}{ Exacerbations in the 6 months prior to entry, $n(\%)^{a}$} \\
\hline 0 & $289(76.9)$ & $167(83.1)$ & $369(78.8)$ & $326(81.5)$ \\
\hline I & $66(17.6)$ & $27(13.4)$ & $77(16.5)$ & $59(14.8)$ \\
\hline$\geq 2$ & $21(5.6)$ & $7(3.5)$ & $22(4.7)$ & $15(3.8)$ \\
\hline mMRC score & $1.7 \pm 1.0$ & $1.7 \pm 0.9$ & $1.9 \pm 1.0$ & $1.8 \pm 1.0$ \\
\hline \multicolumn{5}{|l|}{ mMRC score, n (\%) } \\
\hline $0-1$ & $172(45.7)$ & $88(43.8)$ & $167(35.7)$ & $156(39.0)$ \\
\hline$\geq 2$ & $204(54.3)$ & $113(56.2)$ & $301(64.3)$ & $244(61.0)$ \\
\hline CAT total score & $19.9 \pm 6.8$ & $17.7 \pm 6.4$ & $20.3 \pm 6.5$ & $19.0 \pm 6.8$ \\
\hline \multicolumn{5}{|l|}{ CAT total score, $\mathrm{n}(\%)^{\mathrm{a}}$} \\
\hline$<10$ & $26(7.0)$ & $15(7.5)$ & $26(5.5)$ & $36(9.1)$ \\
\hline $10-20$ & $157(4 \mid .8)$ & $117(58.2)$ & $200(42.7)$ & $192(48.0)$ \\
\hline $21-30$ & $178(47.3)$ & $62(30.8)$ & $227(48.5)$ & $160(40.0)$ \\
\hline$>30$ & $15(4.0)$ & $7(3.5)$ & $15(3.2)$ & $12(3.0)$ \\
\hline \multicolumn{5}{|l|}{ Comorbidities, n (\%) } \\
\hline Alpha-I antitrypsin deficiency & 0 & 0 & $\mathrm{I}(0.2)$ & $\mathrm{I}(0.3)$ \\
\hline Bronchiectasis & $2(0.5)$ & 0 & $6(1.3)$ & $3(0.8)$ \\
\hline Bronchial carcinoma & $3(0.8)$ & $3(1.5)$ & $7(1.5)$ & $9(2.3)$ \\
\hline Cardiovascular disease & $217(57.7)$ & $126(62.7)$ & $235(50.2)$ & $221(55.3)$ \\
\hline Diabetes mellitus type 2 & $69(18.4)$ & $34(16.9)$ & $75(16.0)$ & $55(13.8)$ \\
\hline Osteoporosis & $15(4.0)$ & $14(7.0)$ & $19(4.1)$ & $26(6.5)$ \\
\hline Psychiatric disorders & $23(6.1)$ & $12(6.0)$ & $22(4.7)$ & $29(7.3)$ \\
\hline Sleep apnea & $27(7.2)$ & $21(10.4)$ & $29(6.2)$ & $31(7.8)$ \\
\hline
\end{tabular}

Notes: Data are mean \pm SD, unless stated otherwise. aParameters included in the original pair matching. ${ }^{\circ}$ Random spirometry, assessed without requirement for washout of COPD medication or additional inhalation of short-acting $\beta_{2}$-agonist.

Abbreviations: BMI, body mass index; CAT, COPD Assessment Test; FEV muscarinic antagonist; mMRC, modified Medical Research Council dyspnea scale.

the highest percentage with a clinically relevant worsening in health status. Taken together, these data suggest that the more classes of COPD maintenance therapy a patient already receives, the lower is the benefit from the addition of a drug class - in other words, there is less room for improvement.
Given that one of the few inclusion criteria for DACCORD was initiation or change in maintenance COPD therapy, although we describe two of the groups as "stayed on", this was at therapeutic class only, with all of these patients having a change in at least one of the molecules 


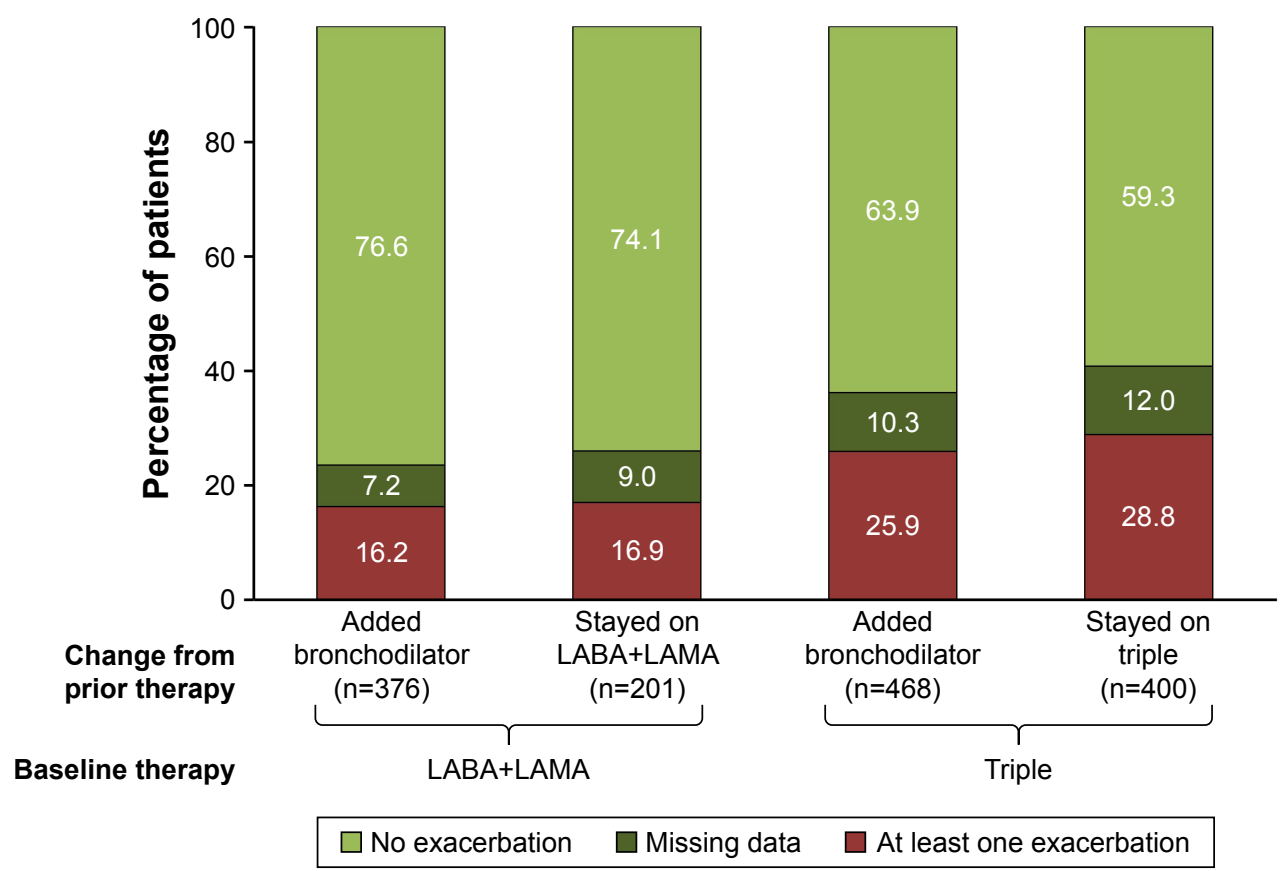

Figure 3 Percentage of patients reporting exacerbations over the I-year follow-up in patients subgrouped according to prior therapy. Abbreviations: LABA, long-acting $\beta_{2}$-agonist; LAMA, long-acting muscarinic antagonist.

within these classes. Since not all LABAs, LAMAs, and ICSs are the same (and are delivered via a range of inhalers), this may complicate the comparisons of the four groups, and is a partial limitation of the analyses, although it reflects real-life practice, in that patients and physicians change medications within the same class, often with accompanying changes in inhalers. However, it may help to explain the clinically relevant improvement in health status seen in two-fifths of patients who stayed on triple therapy. The most common prior medication in this group was a twice-daily ICS/LABA

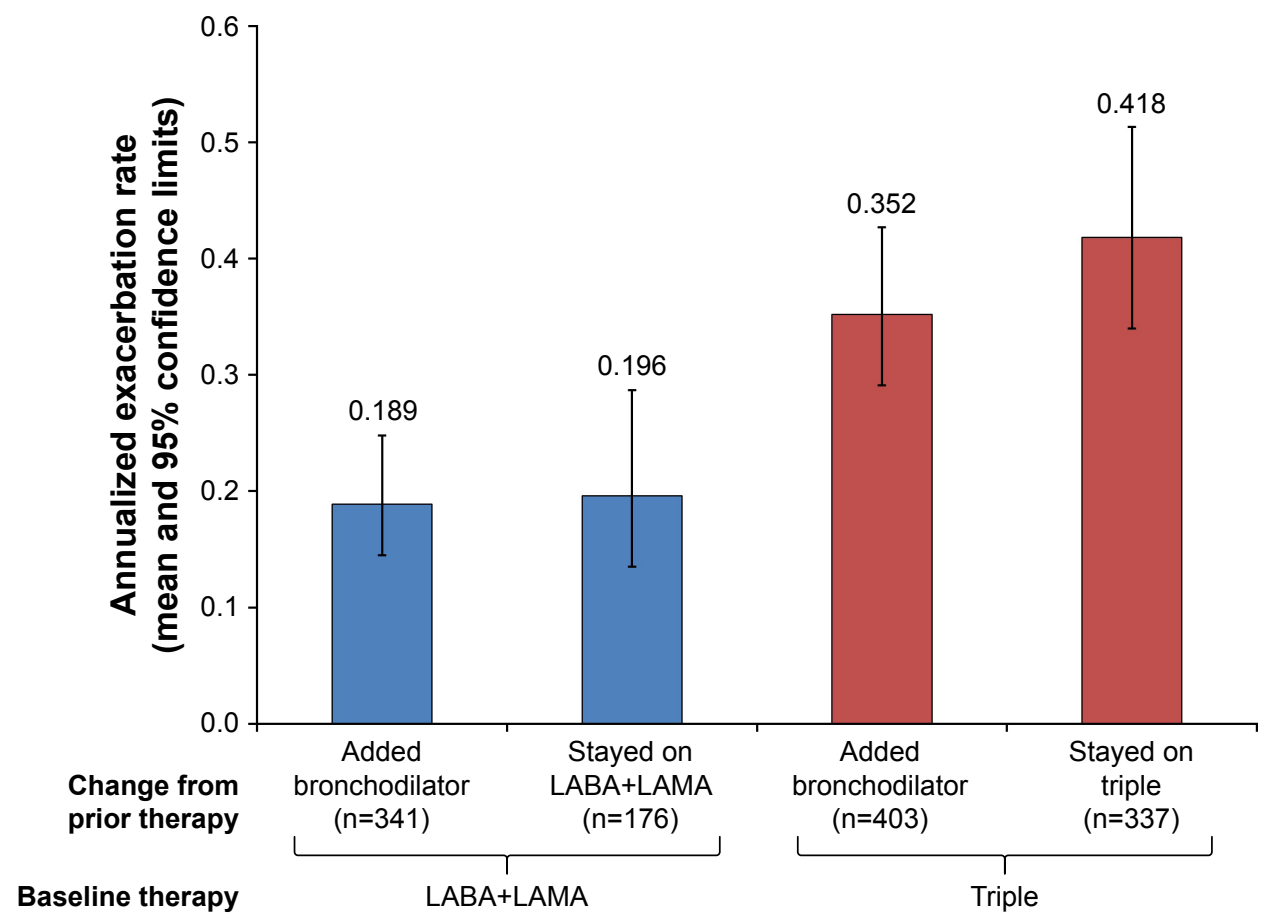

Figure 4 Annualized moderate and severe exacerbation rates in patients subgrouped according to prior therapy. Abbreviations: LABA, long-acting $\beta_{2}$-agonist; LAMA, long-acting muscarinic antagonist. 
Table 2 CAT total score at month 12 - change from baseline in total score and responder analysis in patients subgrouped according to prior therapy

\begin{tabular}{|c|c|c|c|c|}
\hline \multirow{2}{*}{$\begin{array}{l}\text { Baseline therapy } \\
\text { Change from prior therapy }\end{array}$} & \multicolumn{2}{|l|}{ LABA+LAMA } & \multicolumn{2}{|l|}{ Triple } \\
\hline & $\begin{array}{l}\text { Added } \\
\text { bronchodilator } \\
(n=376)\end{array}$ & $\begin{array}{l}\text { Stayed on } \\
\text { LABA+LAMA } \\
(n=20 I)\end{array}$ & $\begin{array}{l}\text { Added } \\
\text { bronchodilator } \\
(n=468)\end{array}$ & $\begin{array}{l}\text { Stayed } \\
\text { on triple } \\
(n=400)\end{array}$ \\
\hline $\begin{array}{l}\text { Change from baseline in CAT } \\
\text { total score, mean } \pm S D\end{array}$ & $-3.3 \pm 6.0$ & $-1.5 \pm 5.5$ & $-1.6 \pm 5.2$ & $-0.9 \pm 6.0$ \\
\hline \multicolumn{5}{|l|}{ Responder analysis, $\mathrm{n}(\%)^{\mathrm{a}}$} \\
\hline Clinically relevant improvement & $244(64.9)$ & $100(49.8)$ & $229(48.9)$ & $164(41.0)$ \\
\hline Clinically relevant worsening & $61(16.2)$ & $48(23.9)$ & $89(19.0)$ & $122(30.5)$ \\
\hline
\end{tabular}

plus a once-daily LAMA; on entry to DACCORD, many of these patients had initiated a once-daily LABA/LAMA FDC plus an ICS. The benefit could, therefore, be a simple trial effect, ${ }^{12-14}$ or could reflect the improved efficacy of oncedaily compared with "older" twice-daily equivalents. ${ }^{11,15-18}$ However, as adherence is not measured in DACCORD, we cannot exclude the possibility that the results could be explained by potential differences in adherence from oncedaily vs twice-daily dosing, or from the use of separate inhalers compared with FDCs. In particular, since no single inhaler triple therapy was available at the time of recruitment into DACCORD, patients in the triple therapy groups had to be using at least two inhalers. Poor adherence could, therefore, potentially impact these patients more than those in the LABA+LAMA groups.

A number of interventional, randomized controlled trials have demonstrated the potential benefit of triple therapy in the management of COPD, including TRILOGY and FULFIL, ${ }^{19,20}$ which compared triple therapy with ICS/LABA, TRINITY, ${ }^{21}$ which compared single-inhaler and multiple inhaler triple therapy with LAMA monotherapy, TRIBUTE, ${ }^{3}$ which compared triple therapy with LABA/LAMA, and IMPACT,${ }^{4}$ which compared triple therapy with ICS/LABA and LABA/LAMA. These studies consistently demonstrated a benefit of triple therapy, especially in terms of exacerbations (especially in patients with higher blood eosinophil levels), with many also suggesting a benefit in terms of health status. However, these studies recruited populations that had an exacerbation history - and although this is consistent with the GOLD recommendations for initial therapy, these are not necessarily the patients who receive triple therapy in "real-life" practice. Indeed, a number of database analyses have indicated that there is a gradual creep in COPD maintenance therapy, with a high proportion of patients eventually receiving triple therapy even in the absence of a history of exacerbations. ${ }^{22,23}$ This disparity between the recruited populations may help to explain some of the differences in results between the previous randomized controlled trials and this analysis of DACCORD. A previous database analysis in GOLD group A and B patients (ie, patients at low risk of future exacerbations) used a similar method to select two matched subgroups, one receiving ICS and the other nonICS containing therapy. ${ }^{24}$ Despite similar overall outcomes, ICS use was associated with significantly increased health care resource utilization, with the authors concluding "using ICS according to GOLD recommendations may offer an opportunity for improving patient care and reducing resource use". ${ }^{24}$ Importantly, a number of studies have demonstrated that ICS can be withdrawn without deleterious consequences in appropriately selected patients (in particular, those who are not frequently exacerbating). ${ }^{2,25}$

There is growing evidence that a group of patients with COPD do not benefit from ICS as their disease mechanisms are not steroid responsive, with some analyses suggesting that only patients with high levels of eosinophils respond to such therapy. ${ }^{3,26-28}$ This may help to explain the relatively poor results in the two triple therapy subgroups in DACCORD - especially given recent data that suggest triple therapy can reduce the rate of exacerbations compared with dual bronchodilation. ${ }^{3}$ It is also possible that these patients were at a later disease stage and/or had more severe disease than those on bronchodilator monotherapy - as suggested by the higher proportion of patients who had been diagnosed $>1$ year prior to entry and who had worse mMRC scores (unfortunately, neither more detail on disease duration nor imaging data are captured in DACCORD). However, a substantial proportion of these patients had not exacerbated in the 6 months prior to entering DACCORD; these patients could potentially be categorized as being GOLD groups A or B, for whom ICS-containing therapy would not 
be recommended - although we do not know why the ICS was initially prescribed for these patients. It is of note that the GOLD strategy document suggests that one option for patients who continue to exacerbate despite triple therapy is to stop ICS, given a reported lack of efficacy, an elevated risk of adverse effects, and evidence showing no significant harm from withdrawal. ${ }^{2,25,29}$

The analyses included less than one-fifth of the overall DACCORD population completing 1 year. However, most of the patients were excluded on the basis of their medication (rather than through the pair-matching process). We, therefore, believe that the population we analyzed is representative of patients receiving only dual bronchodilation or inhaled triple therapy in the real world, even though more than half of the patients had mild or moderate airflow limitation. Further, since at the time recruitment commenced into the LABA+LAMA group, the only FDC LABA+LAMA on the market was indacaterol + glycopyrronium, the results we observed may not extrapolate to all such combinations. Indeed, in a recent Cochrane review comparing LABA+LAMA combinations with $\mathrm{LABA}+\mathrm{ICS}$, although most of the LABA+LAMA combinations had a similar effect on health status (assessed using the St George's Respiratory Questionnaire), only indacaterol + glycopyrronium reduced the rate of COPD exacerbations. ${ }^{30} \mathrm{~A}$ possible source of bias is that the decision to change medication (and the medication change itself) was made by each patient's physician - and the reason for the change in medication was not captured in the study database. Although we have clearly demonstrated that prior medication influenced the subsequent results, we cannot use these data to "adjust" or "correct" the results of controlled clinical trials. The "real-life" nature of the study is also a potential source of bias, since although we used an extensive list of parameters in the matched-pairs approach, we cannot completely exclude the possibility that the groups differed in terms of other unmeasured characteristics.

\section{Conclusion}

In this "real-life" cohort of patients with COPD, most of whom had not exacerbated in the 6 months prior to entry, triple therapy did not seem to improve outcomes compared with LABA+LAMA in terms of either exacerbations or health status. Our analyses suggest that the greatest benefit from the COPD maintenance therapy change on entry to DACCORD was in those patients who added a second bronchodilator to a single bronchodilator to receive dual bronchodilation (ie, effectively doubling the therapy they received). This benefit was greater than those who added another bronchodilator to an ICS plus bronchodilator therapy (mostly ICS/LABA) to receive triple therapy. The group of patients who stayed on triple were at the highest risk of the four groups in exacerbating, despite the groups being matched on a range of baseline characteristics. Finally, our analyses clearly demonstrate the potential impact of prior medication on study results, something that should be taken into account when interpreting the results even of controlled clinical trials.

\section{Data sharing statement}

Patient-level data are not publicly available since DACCORD is ongoing.

\section{Acknowledgments}

The authors would like to thank the investigators and patients at the investigative sites for their support of this study. Writing support was provided by David Young of Young Medical Communications and Consulting Ltd. This support was funded by Novartis Pharma GmbH. This study was funded by Novartis Pharma GmbH. Employees of the sponsor were involved in study design, data analysis, and interpretation, and oversaw the conduct of the study, and (as authors) contributed to the development of this manuscript.

\section{Disclosure}

Dr Buhl reports personal fees from AstraZeneca, Chiesi, Teva, and Cipla, grants and personal fees from Boehringer Ingelheim, Novartis, and Roche, and grants from GlaxoSmithKline, all of which are outside the submitted work. Dr Criée reports personal fees from Chiesi, Boehringer Ingelheim, Novartis, Menarini, and Takeda, all of which are outside the submitted work. Dr Kardos reports personal fees from Novartis, AstraZeneca, Boehringer Ingelheim, Chiesi, GSK, Menarini, and Takeda, all of which are outside the submitted work. Dr Vogelmeier reports personal fees from Almirall, Cipla, Berlin Chemie/Menarini, CSL Behring, and Teva, grants and personal fees from AstraZeneca, Boehringer Ingelheim, Chiesi, GlaxoSmithKline, Grifols, Mundipharma, Novartis, and Takeda, and grants from the German Federal Ministry of Education and Research (BMBF) Competence Network Asthma and COPD (ASCONET), Bayer Schering Pharma AG, MSD, and Pfizer, all of which are outside the submitted work. Dr Kostikas is employed by, and is a stockholder in Novartis, the sponsor of the study. Outside the submitted work, he reports personal fees from Astra Zeneca, Boehringer Ingelheim, Chiesi, ELPEN, Novartis, and Takeda. Dr Lossi is employed by Novartis, the sponsor of the study. Dr Worth reports personal fees from AstraZeneca, Boehringer Ingelheim, Chiesi, GlaxoSmithKline, 
Klosterfrau, Menarini, Novartis, and Takeda, all of which are outside the submitted work. The authors report no other conflicts of interest in this work.

\section{References}

1. Aaron SD, Vandemheen KL, Fergusson D, et al. Tiotropium in combination with placebo, salmeterol, or fluticasone-salmeterol for treatment of chronic obstructive pulmonary disease: a randomized trial. Ann Intern Med. 2007;146(8):545-555.

2. Magnussen H, Disse B, Rodriguez-Roisin R, et al. Withdrawal of inhaled glucocorticoids and exacerbations of COPD. $N$ Engl J Med. 2014; 371(14):1285-1294.

3. Papi A, Vestbo J, Fabbri L, et al. Extrafine inhaled triple therapy versus dual bronchodilator therapy in chronic obstructive pulmonary disease (TRIBUTE): a double-blind, parallel group, randomised controlled trial. Lancet. 2018;391(10125):1076-1084.

4. Lipson DA, Barnhart F, Brealey N, et al. Once-daily single-inhaler triple versus dual therapy in patients with COPD. N Engl J Med. 2018; 378(18):1671-1680.

5. Kardos P, Vogelmeier C, Buhl R, Criée CP, Worth H. The prospective non-interventional DACCORD study in the National COPD Registry in Germany: design and methods. BMC Pulm Med. 2015;15(1):2.

6. Buhl R, Criée CP, Kardos P, et al. A year in the life of German patients with COPD: the DACCORD observational study. Int J Chron Obstruct Pulmon Dis. 2016;11(1):1639-1646.

7. Vogelmeier C, Worth H, Buhl R, et al. "Real-life" inhaled corticosteroid withdrawal in COPD: a subgroup analysis of DACCORD. Int J Chron Obstruct Pulmon Dis. 2017;12:487-494.

8. Worth H, Buhl R, Criée CP, Kardos P, Mailänder C, Vogelmeier C. The 'real-life' COPD patient in Germany: the DACCORD study. Respir Med. 2016;111:64-71.

9. Kardos P, Vogelmeier C, Worth H, et al. A two-year evaluation of the 'real life' impact of COPD on patients in Germany: the DACCORD observational study. Respir Med. 2017;124:57-64.

10. Worth H, Buhl R, Criée C-P, Kardos P, Lossi NS, Vogelmeier CF. GOLD 2017 treatment pathways in 'real life': an analysis of the DACCORD observational study. Respir Med. 2017;2017(131):77-84.

11. Wedzicha JA, Banerji D, Chapman KR, et al. Indacaterol-glycopyrronium versus salmeterol-fluticasone for COPD. N Engl J Med. 2016;374(23): 2222-2234.

12. Landsberger HA. Hawthorne Revisited. New York: The New York State School of Industrial and Labor Relations; 1958.

13. McCarney R, Warner J, Iliffe S, van Haselen R, Griffin M, Fisher P. The Hawthorne effect: a randomised, controlled trial. BMC Med Res Methodol. 2007;7(1):30.

14. Jones PW, Gelhorn H, Wilson H, et al. Effect of bronchodilator and placebo therapy on SGRQ score in patients over 3 years: difference between low/medium and high socio-economic countries. Am J Respir Crit Care Med. 2014;189:A5962.s

15. Dahl R, Chung KF, Buhl R, et al. Efficacy of a new once-daily longacting inhaled beta2-agonist indacaterol versus twice-daily formoterol in COPD. Thorax. 2010;65(6):473-479.

16. Kornmann O, Dahl R, Centanni S, et al. Once-daily indacaterol versus twice-daily salmeterol for COPD: a placebo-controlled comparison. Eur Respir J. 2011;37(2):273-279.
17. Cope S, Donohue JF, Jansen JP, et al. Comparative efficacy of longacting bronchodilators for COPD: a network meta-analysis. Respir Res. 2013;14:100.

18. Buhl R, Gessner C, Schuermann W, et al. Efficacy and safety of once-daily QVA149 compared with the free combination of once-daily tiotropium plus twice-daily formoterol in patients with moderate-to-severe COPD (QUANTIFY): a randomised, non-inferiority study. Thorax. 2015; 70(4):311-319.

19. Singh D, Papi A, Corradi M, et al. Single inhaler triple therapy versus inhaled corticosteroid plus long-acting $\beta 2$-agonist therapy for chronic obstructive pulmonary disease (TRILOGY): a double-blind, parallel group, randomised controlled trial. Lancet. 2016;388(10048): 963-973.

20. Lipson DA, Barnacle H, Birk R, et al. FULFIL trial: once-daily triple therapy for patients with chronic obstructive pulmonary disease. Am J Respir Crit Care Med. 2017;196(4):438-446.

21. Vestbo J, Papi A, Corradi M, et al. Single inhaler extrafine triple therapy versus long-acting muscarinic antagonist therapy for chronic obstructive pulmonary disease (TRINITY): a double-blind, parallel group, randomised controlled trial. Lancet. 2017;389(10082):1919-1929.

22. Brusselle G, Price D, Gruffydd-Jones K, et al. The inevitable drift to triple therapy in COPD: an analysis of prescribing pathways in the UK. Int J Chron Obstruct Pulmon Dis. 2015;10(1):2207-2217.

23. Price D, West D, Brusselle G, et al. Management of COPD in the UK primary-care setting: an analysis of real-life prescribing patterns. Int $J$ Chron Obstruct Pulmon Dis. 2014;9:889-905.

24. Chalmers JD, Poole C, Webster S, Tebboth A, Dickinson S, Gayle A. Assessing the healthcare resource use associated with inappropriate prescribing of inhaled corticosteroids for people with chronic obstructive pulmonary disease (COPD) in GOLD groups A or B: an observational study using the Clinical Practice Research Datalink (CPRD). Respir Res. 2018;19(1):63.

25. Chapman KR, Hurst JR, Frent SM, et al. Long-term triple therapy deescalation to indacaterol/glycopyrronium in COPD Patients (SUNSET): a randomized, double-blind, triple-dummy clinical trial. Am J Respir Crit Care Med. Epub 2018 May 20.

26. Siddiqui SH, Guasconi A, Vestbo J, et al. Blood eosinophils: a biomarker of response to extrafine beclomethasone/formoterol in chronic obstructive pulmonary disease. Am J Respir Crit Care Med. 2015;192(4): 523-525.

27. Pavord ID, Lettis S, Locantore N, et al. Blood eosinophils and inhaled corticosteroid/long-acting $\beta$-2 agonist efficacy in COPD. Thorax. 2016; 71(2):118-125.

28. Leigh R, Pizzichini MM, Morris MM, Maltais F, Hargreave FE, Pizzichini E. Stable COPD: predicting benefit from high-dose inhaled corticosteroid treatment. Eur Respir J. 2006;27(5):964-971.

29. Global Initiative for Chronic Obstructive Lung Disease. Global strategy for the diagnosis, management, and prevention of chronic obstructive pulmonary disease. 2018. Available from: www.goldcopd.org. Accessed December 12, 2017.

30. Horita N, Goto A, Shibata Y, et al. Long-acting muscarinic antagonist (LAMA) plus long-acting beta-agonist (LABA) versus LABA plus inhaled corticosteroid (ICS) for stable chronic obstructive pulmonary disease (COPD). Cochrane Database Syst Rev. 2017;2:CD012066. 


\section{Supplementary material}

Table SI Baseline demographics and disease characteristics of patients, overall and in the matched-pairs analysis

\begin{tabular}{|c|c|c|c|c|c|}
\hline \multirow[t]{2}{*}{ Parameter } & \multicolumn{2}{|l|}{ Overall } & \multicolumn{3}{|l|}{ Matched pairs } \\
\hline & $\begin{array}{l}\text { LABA+LAMA } \\
(n=2,885)\end{array}$ & $\begin{array}{l}\text { Triple } \\
(n=I, 3 \mid I)\end{array}$ & $\begin{array}{l}\text { LABA+LAMA } \\
(n=1,046)\end{array}$ & $\begin{array}{l}\text { Triple } \\
(n=1,046)\end{array}$ & $P$-value \\
\hline \multicolumn{6}{|l|}{ Gender, n (\%) ${ }^{\mathrm{a}}$} \\
\hline Male & I,747 (60.6) & 799 (60.9) & $662(63.3)$ & $662(63.2)$ & $0.999^{\mathrm{b}}$ \\
\hline Age (years) ${ }^{\mathrm{a}}$ & $66.2 \pm 10.1$ & $66.7 \pm 10.1$ & $66.5 \pm 9.8$ & $66.8 \pm 10.0$ & $0.506^{c}$ \\
\hline Age groups, n (\%) & & & & & $0.956^{b}$ \\
\hline$<65$ & $\mathrm{I}, 269(44.0)$ & $55 I(42.0)$ & $438(4 I .9)$ & $438(41.9)$ & \\
\hline $65-75$ & $\mathrm{I}, 03 \mathrm{I}(35.7)$ & $493(37.6)$ & $398(38.0)$ & $393(37.6)$ & \\
\hline$>75$ & $585(20.3)$ & $267(20.4)$ & $210(20.1)$ & $215(20.6)$ & \\
\hline BMI $\left(\mathrm{kg} / \mathrm{m}^{2}\right)^{\mathrm{a}}$ & $27.6 \pm 5.7$ & $27.2 \pm 5.5$ & $27.6 \pm 5.5$ & $27.4 \pm 5.3$ & $0.488^{c}$ \\
\hline \multicolumn{3}{|l|}{ Time since primary diagnosis, n (\%) } & & & $<0.00 I^{\mathrm{b}}$ \\
\hline$\leq \mathrm{I}$ year & $809(28.0)$ & $231(17.6)$ & $272(26.0)$ & $188(18.0)$ & \\
\hline$>$ I year & $2,076(72.0)$ & $1,080(82.4)$ & $774(74.0)$ & $858(82.0)$ & \\
\hline \multicolumn{3}{|l|}{ Smoking history, $\mathrm{n}(\%)^{\mathrm{a}}$} & & & $0.999^{b}$ \\
\hline Ex-smoker & I,I $76(40.8)$ & $638(48.7)$ & $525(50.2)$ & $525(50.2)$ & \\
\hline Current smoker & I,I7I (40.6) & $450(34.3)$ & $368(35.2)$ & $368(35.2)$ & \\
\hline Non-smoker & $533(18.5)$ & $216(16.5)$ & $153(14.6)$ & $153(14.6)$ & \\
\hline \multicolumn{3}{|l|}{$\mathrm{FEV}, \%$ predicted, $\mathrm{n}(\%)^{\mathrm{a}, \mathrm{d}}$} & & & $0.999^{b}$ \\
\hline$\geq 80 \%$ & $559(19.4)$ & $161(12.3)$ & $129(12.3)$ & $129(12.3)$ & \\
\hline $50 \leq \mathrm{FEV}_{1}<80 \%$ & I,57| (54.5) & $680(51.9)$ & $598(57.2)$ & $598(57.2)$ & \\
\hline $30 \leq \mathrm{FEV}_{1}<50 \%$ & $659(22.8)$ & $392(29.9)$ & $292(27.9)$ & $292(27.9)$ & \\
\hline$<30 \%$ & $96(3.3)$ & $78(5.9)$ & $27(2.6)$ & $27(2.6)$ & \\
\hline \multicolumn{3}{|c|}{ Exacerbations in the 6 months prior to entry, $\mathrm{n}(\%)^{\mathrm{a}}$} & & & $0.626^{\mathrm{b}}$ \\
\hline 0 & $2,254(78.1)$ & $927(70.7)$ & $824(78.8)$ & $824(78.8)$ & \\
\hline 1 & $443(15.4)$ & $259(19.8)$ & $169(16.2)$ & $169(16.2)$ & \\
\hline$\geq 2$ & $164(5.7)$ & $113(8.6)$ & $53(5.1)$ & $53(5.1)$ & \\
\hline mMRC score & $1.6 \pm 1.0$ & $1.9 \pm 1.0$ & $1.7 \pm 1.0$ & $1.9 \pm 1.0$ & $0.002^{c}$ \\
\hline \multicolumn{2}{|l|}{ mMRC score, n (\%) } & & & & $0.008^{\mathrm{b}}$ \\
\hline $0-1$ & I,365 (47.3) & 470 (35.9) & $447(42.7)$ & $388(37.1)$ & \\
\hline$\geq 2$ & $1,520(52.7)$ & $84 I(64.1)$ & $599(57.3)$ & $658(62.9)$ & \\
\hline CAT total score & $18.7 \pm 7.6$ & $20.7 \pm 7.2$ & $19.6 \pm 6.8$ & $20.1 \pm 6.7$ & $0.123^{c}$ \\
\hline \multicolumn{2}{|l|}{ CAT total score, $\mathrm{n}(\%)^{\mathrm{a}}$} & & & & $0.985^{\mathrm{b}}$ \\
\hline$<10$ & $365(12.7)$ & $92(7.0)$ & $71(6.8)$ & $7 I(6.8)$ & \\
\hline $10-20$ & $\mathrm{I}, 30 \mathrm{I}(45 . \mathrm{I})$ & $537(4 I .0)$ & $459(43.9)$ & $459(43.9)$ & \\
\hline $21-30$ & $1,039(36.0)$ & $582(44.4)$ & $472(45.1)$ & $472(45.1)$ & \\
\hline$>30$ & $180(6.2)$ & $100(7.6)$ & $44(4.2)$ & $44(4.2)$ & \\
\hline \multicolumn{6}{|l|}{ Comorbidities, n (\%) } \\
\hline None & $567(19.7)$ & $254(19.4)$ & $208(19.9)$ & $211(20.2)$ & $0.870^{\mathrm{b}}$ \\
\hline Alpha-I antitrypsin deficiency & $2(0.1)$ & $3(0.2)$ & $\mathrm{I}(0 . \mathrm{I})$ & $2(0.2)$ & $0.538^{\mathrm{b}, \mathrm{e}}$ \\
\hline Bronchiectasis & $24(0.8)$ & $20(1.5)$ & $4(0.4)$ & $10(1.0)$ & $0.087^{b, e}$ \\
\hline Bronchial carcinoma & $36(1.2)$ & $26(2.0)$ & $16(1.5)$ & $19(1.8)$ & $0.536^{\mathrm{b}, \mathrm{e}}$ \\
\hline Cardiovascular disease & I,639 (56.8) & $712(54.3)$ & $620(59.3)$ & $556(53.2)$ & $0.11 I^{b, e}$ \\
\hline Diabetes mellitus type 2 & $525(18.2)$ & $190(14.5)$ & $203(19.4)$ & $155(14.8)$ & $0.026^{\mathrm{b}, \mathrm{e}}$ \\
\hline Osteoporosis & $|7|(5.9)$ & $78(5.9)$ & $66(6.3)$ & $56(5.4)$ & $0.810^{\mathrm{b}, \mathrm{e}}$ \\
\hline Psychiatric disorders & $258(8.9)$ & $107(8.2)$ & $79(7.6)$ & $68(6.5)$ & $0.745^{\mathrm{b}, \mathrm{e}}$ \\
\hline Sleep apnea & $251(8.7)$ & $99(7.6)$ & $86(8.2)$ & $80(7.6)$ & $0.875^{b, e}$ \\
\hline
\end{tabular}

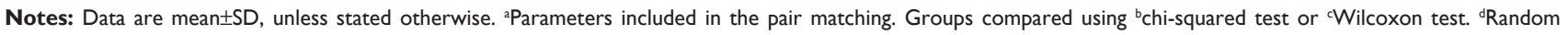
spirometry, assessed without requirement for washout of COPD medication or additional inhalation of short-acting $\beta_{2}$-agonist. eP-values calculated in the population excluding those with all entries blank on the case report form.

Abbreviations: BMI, body mass index; CAT, COPD Assessment Test; FEV , forced expiratory volume in I second; LABA, long-acting $\beta_{2}$-agonist; LAMA, long-acting muscarinic antagonist; mMRC, modified Medical Research Council dyspnea scale. 


\section{Publish your work in this journal}

The International Journal of COPD is an international, peer-reviewed journal of therapeutics and pharmacology focusing on concise rapid reporting of clinical studies and reviews in COPD. Special focus is given to the pathophysiological processes underlying the disease, intervention programs, patient focused education, and self management protocols.

This journal is indexed on PubMed Central, MedLine and CAS. The manuscript management system is completely online and includes a very quick and fair peer-review system, which is all easy to use. Visit http://www.dovepress.com/testimonials.php to read real quotes from published authors.

Submit your manuscript here: http://www.dovepress.com/international-journal-of-chronic-obstructive-pulmonary-disease-journal 